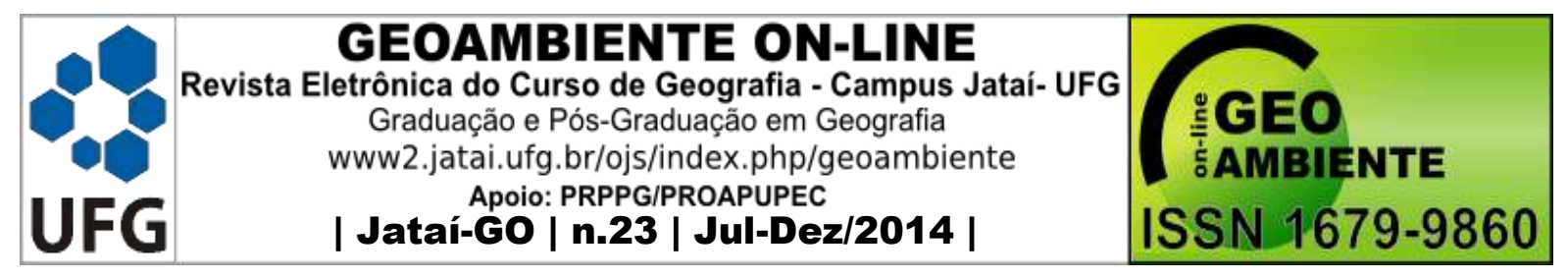

\title{
DESCRIÇÃO GEOLÓGICA DA BACIA HIDROGRÁFICA DO CÓRREGO DAS VACAS EM DIORAMA - GO
}

Derick Martins Borges de Moura ${ }^{1}$, Flávio Alves de Sousa ${ }^{2}$

(1 - Secretaria do Meio Ambiente e dos Recursos Hídricos do Estado de Goiás - SEMARHGO, Geógrafo, derick-mb@semarh.goias.gov.br; 2 - Universidade do Estado de Goiás Campus Iporá, Docente do Curso de Geografia, flavio.alves@ueg.br)

\section{Resumo}

Este trabalho faz uma análise da geologia da bacia hidrográfica do córrego das Vacas, que se diferencia das demais bacias em volta por demonstrar uma morfologia em forma de anfiteatro, enquanto as demais apresentam limites mais rebaixados e abertos. Dessa maneira o presente estudo teve por objetivo, compreender a estrutura geológica de formação da bacia de drenagem, e que fatores contribuíram para a forma diferenciada da mesma, levando em consideração a erosão diferencial em função das diferentes resistências litológicas ao intemperismo. Para isso, foram utilizados métodos de descrição petrográfica, geotecnológicos de mapeamento e revisões bibliográficas para entender melhor os aspectos geológicos e geomorfológicos. Os levantamentos cartográficos e bibliográficos tiveram ainda o subsídio de incursão em campo, visando o controle das informações cartográficas e levantamento de informações que não foram visualizadas em mapas. Foram confeccionados diversos mapas temáticos da bacia, que acompanhado das análises bibliográficas e de campo, auxiliaram a entender que a bacia teve sua morfologia esculpida por erosão diferencial como as demais, porém, as litologias presentes na bacia são mais diversificadas, com diferentes idades e resistências, dando à bacia uma morfologia diferenciada.

Palavras-chave: Morfologia. Geologia. Relevo.

\section{Abstract}

GEOLOGICAL DESCRIPTION THE HIDROGRAPHIC BASIN OF STREAM OF VACAS IN DIORAMA-BRAZIL.

\footnotetext{
Artigo recebido para publicação em 29 de Outubro de 2014

Artigo aprovado para publicação em 29 de Dezembro de 2014
} 


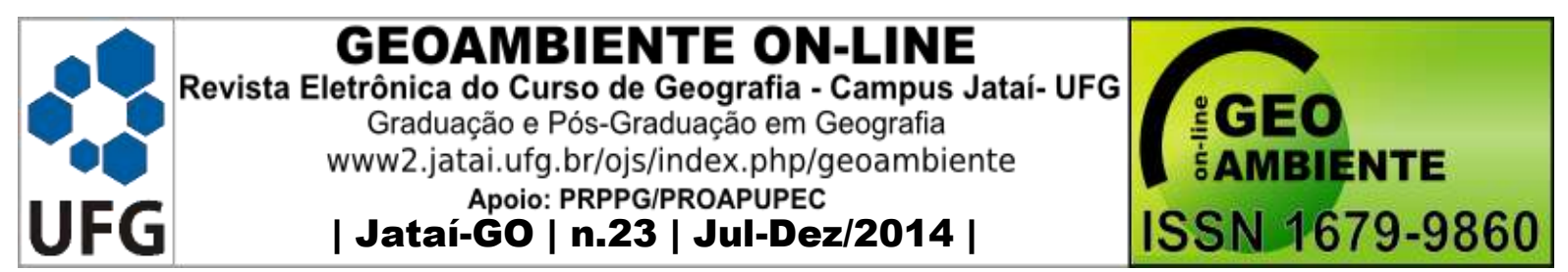

This paper presents an analysis of the geology of the Vacas drainage basin. It varies from the other basins nearby; it exhibits an amphitheatre shape while the others have recessed and open margins. This study aims to understand the formation processes behind the geology of the drainage basins and what factors contribute to the Vacas drainage basin shape. Using previous research and geological and advanced mapping methods the rock types were determined and from this the differential weathering and erosion rates were calculated. These results, along with previous maps of the area, were used to understand how the Vacas drainage basin formed a different morphology to the others. It was concluded that the lithologies in the Vacas watershed are more diverse than the other watersheds, with rocks of various ages and strengths, which is why the morphology is bowl shaped.

Keywords: Morphology. Geology. Relief.

\section{Resumen}

\section{DESCRIPCIÓN GEOLÓGICA DE LA CUENCA DEL ARROYO DE LAS VACAS EN DIORAMA-BRASIL.}

Este trabajo hace una análisis de la geología de la cuenca del arroyo de las Vacas, que se diferencia de otras cuencas en torno porque muestra una morfología de anfiteatro, mientras que los otros tienen límites más huecos y abiertos. Así, este estudio tiene como objetivo comprender la estructura geológica de formación de la cuenca de drenaje, y qué factores contribuyeron a la diferente forma de la misma, teniendo en cuenta la erosión diferencial debido a la diferente resistencia litológica a la intemperie. Por esto se utilizó métodos de descripción petrográfica, mapeo y revisiones de la literatura para comprender mejor los aspectos geológicos y geomorfológicos. La cartográfica y la bibliografía, dio subsidio en el campo, con el objetivo en el control de la información de los mapas y encuesta de información que no se visualiza en los mapas. Fueran hechos varios mapas temáticos de la cuenca, acompañados de análisis bibliográfico y de campo, ayudaron a comprender que la morfología de la cuenca fue tallado por la erosión diferencial como las otras, sin embargo, las litologías presentes en la cuenca son más diversos, con diferentes edades y fortalezas, dando a la cuenca una morfología diferenciada.

Palabras clave: Morfología. Geología. Relieve.

\section{Introdução}




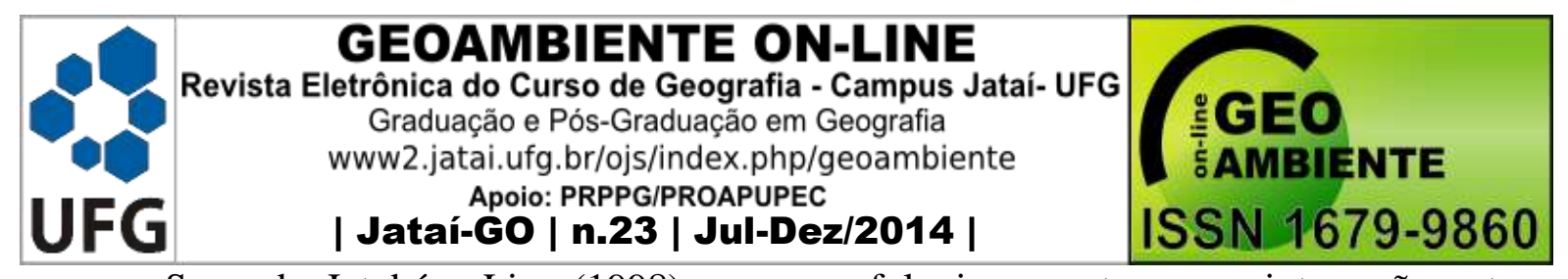

Segundo Jatobá e Lins (1998), a geomorfologia encontra-se na interseção entre a geografia e a geologia, pois há influências endógenas e exógenas na formação do relevo. Por isso, para obter uma interpretação das características geomorfológicas de uma dada área, fazse necessário um conhecimento da estrutura geológica que lhe deu origem.

Netto (2003), diz que um sistema que é frequentemente empregado para delimitar porções de estudo é a bacia hidrográfica, que corresponde a uma área da superfície terrestre que drena águas, sedimentos e materiais dissolvidos para uma saída comum num determinado ponto do canal fluvial, e o seu limite é conhecido como divisor de águas.

Silva (2009) ressalta a função da resistência diferencial da litologia em elaborar superfícies estruturais desniveladas pela erosão em rochas desigualmente friáveis, ou mantidas no mesmo nível altimétrico por influência da estrutura geológica. A erosão diferencial desencadeada pelas condições climáticas e pelos diferentes graus de resistência das rochas ao intemperismo contribui para se formar diferentes fisionomias do relevo.

A caracterização geológico-geomorfológica fica facilitada quando se conhece a composição litológica da área a ser analisada e também as feições geomorfológicas correlatas, o que é possível fazer através da relação de mapeamento e expedições de campo.

Conforme Silva e Rodrigues (2009), para que a análise geomorfológica torne-se melhor compreendida, a mesma deverá vir acompanhada de documentos cartográficos que auxiliem na sua espacialização, pois assim é possível perceber as dimensões das diferentes feições e formas, bem como mensurar a sua influência no espaço analisado.

De acordo com Casseti (2005), a cartografia geomorfológica é um importante instrumento na espacialização dos aspectos físicos do relevo, representando a origem das formas e suas relações com a estrutura e os processos, considerando suas particularidades.

Demek (1967), apud Machado e Lima (2013), considera que o mapeamento para a análise geomorfológica tem se tornado o principal método para o estudo e a pesquisa.

Carvalho e Latrubesse (2004), afirmam que o uso das imagens SRTM (Shuttle Radar Topography Mission) tem se tornado cada vez mais frequente em estudos geológicos, hidrológicos, geomorfológicos, ecológicos, dentre outros, em particular para análises tanto quantitativas como qualitativas do relevo e seus agentes modificadores, em especial na elaboração de mapas hipsométricos.

Segundo Felgueiras (1997), o MDT (Modelo Digital do Terreno), também chamado de modelo de elevação do terreno, conhecidos em inglês por DEM (Digital Elevation Model) ou modelos numéricos do terreno (MNT), possuem diversas aplicações para a geomorfologia, 


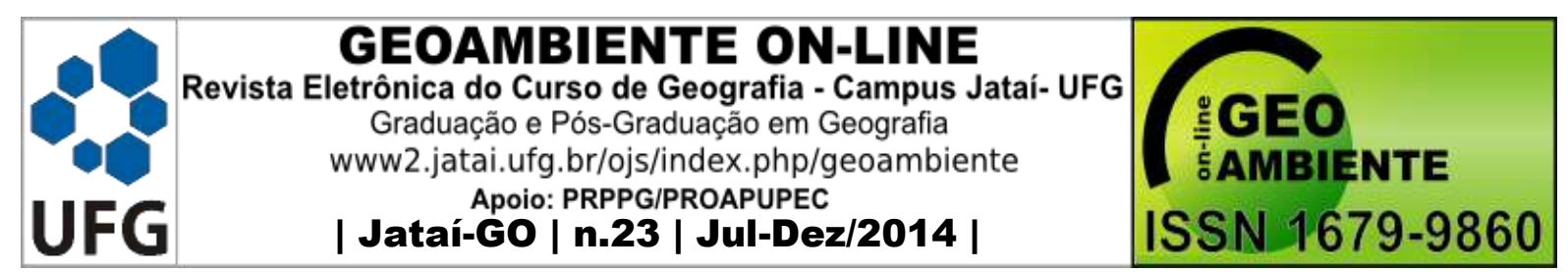

como a elaboração de mapas hipsométricos, elaboração de mapas de declividade, criação e análises de rede hidrográfica nos mapas, delimitação automática de bacias, microbacias e áreas inundadas entre outras funções.

Para Ross (1992), o mapeamento geomorfológico tem por fundamento a ordenação hierárquica dos fatos geomorfológicos, a fim de que possam representá-los em uma metodologia que agrupe os sucessivos conjuntos de modelados de relevo.

Para Jatobá e Lins (1998), o relevo terrestre é um importante componente do quadro natural e seus aspectos físicos particulares, condicionam a distribuição dos solos, da vegetação e até mesmo algumas características climáticas locais. O relevo participa na determinação das possibilidades de aproveitamento dos recursos hídricos, das jazidas minerais e do espaço para os diversos usos do solo pela humanidade.

Nesse sentido, analisar a litologia e a geomorfologia numa bacia hidrográfica tem importante justificativa, pois estes aspectos influenciam diretamente no tipo de uso e ocupação da mesma, bem como determina os tipos de manejo que devem ser realizados na bacia, para que o uso esteja sempre alinhado com a conservação do recursos naturais ali existentes.

A estrutura geológica-geomorfológica da bacia hidrográfica do córrego das Vacas apresenta características geomorfológicas não peculiares, quando comparada com as demais bacias adjacentes. A bacia em questão apresenta divisores assentados sobre estruturas remanescentes de maior altitude e de maior resistência aos processos morfodinâmicos, dando através dos agentes denudacionais uma forma de anfiteatro, não comum em áreas graníticas, como é o caso da região onde a mesma se encontra. A Figura 1 ilustrada a seguir, demonstra a morfologia da bacia que se destaca em relação a outras bacias adjacentes.

Dessa maneira o presente estudo teve por objetivo, compreender o processo de formação da bacia de drenagem, que fatores contribuíram para a forma diferenciada da mesma, o que foi realizado com o auxílio de dados que tivessem como base, parâmetros morfométricos e morfográficos, extraídos do MDE (modelo digital de elevação) TOPODATA do INPE (Instituto Nacional de Pesquisas Espaciais), por dados disponibilizados pela SIEG (Sistema Estadual de Geoinformação de Goiás), CPRM (Companhia de Pesquisa de Recursos Minerais) e por trabalhos de campo, tendo como foco os diferentes graus de resistência da litologia, já que o clima dominante é igual em toda a região, ou seja, Sousa (2013) destaca em sua tese um clima tropical sub-úmido com duas estações bem definidas, uma seca e outra 


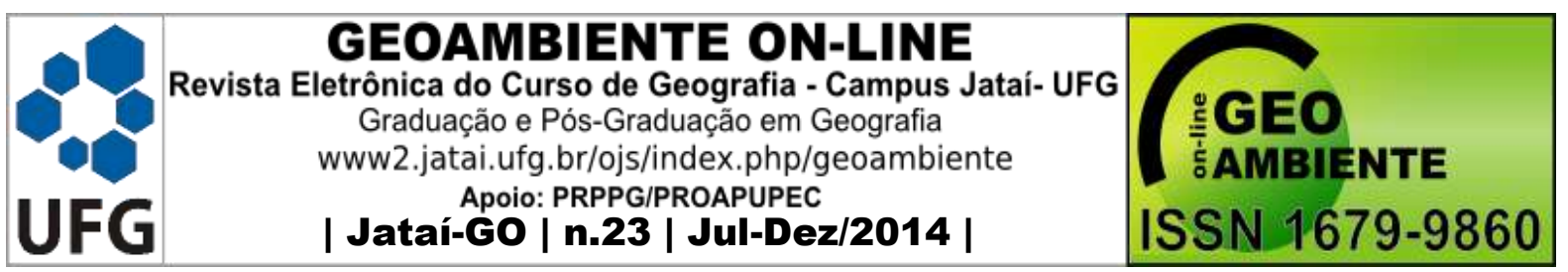

úmida, com chuvas predominando entre outubro a maio e precipitação média de 1680 $\mathrm{mm} / \mathrm{ano}$.

Figura 1: Imagem da Bacia hidrográfica do córrego das Vacas.

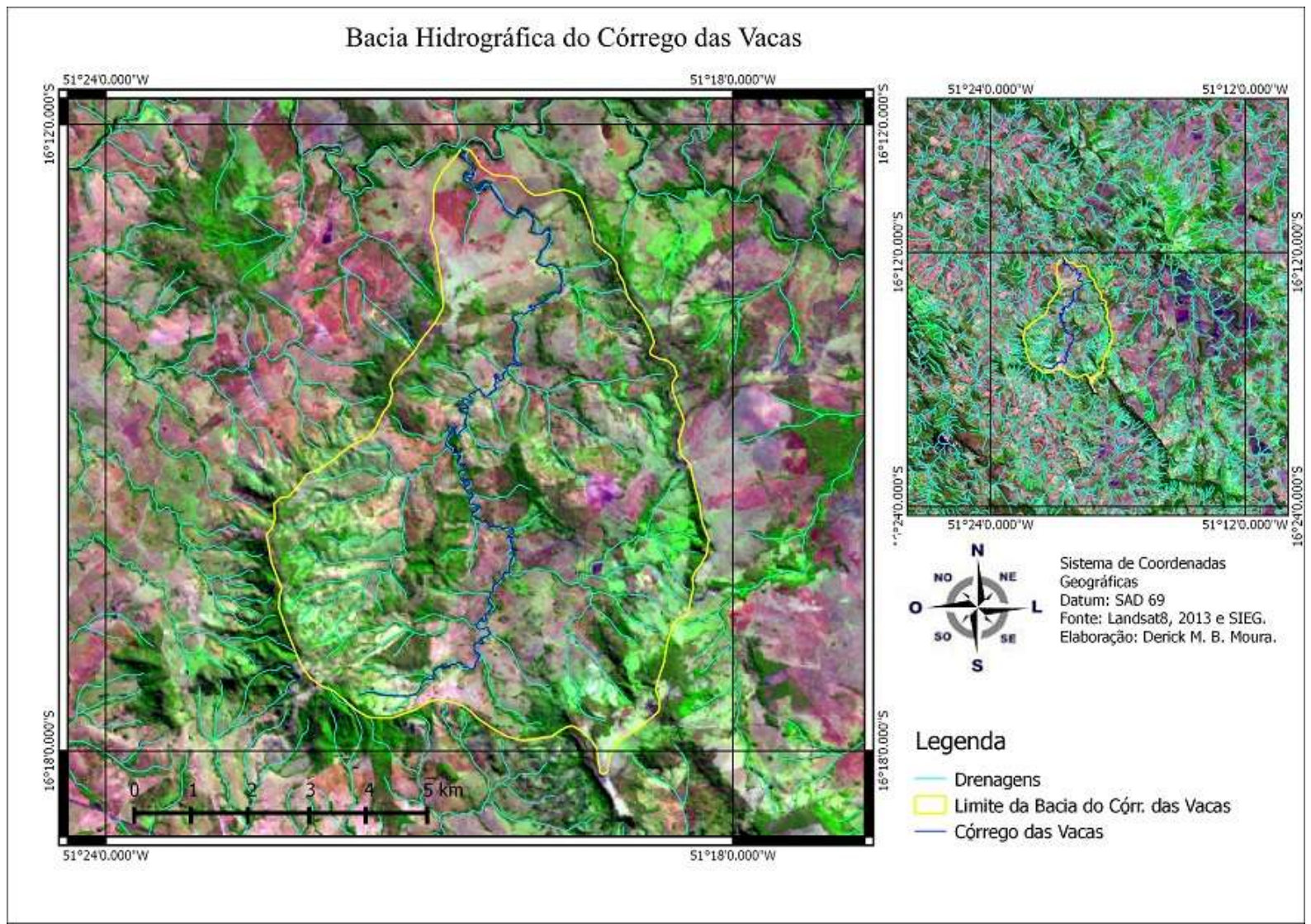

Fonte: Landsat8, 2013 e SIEG. Elaboração: Moura, 2014.

\section{1. Área de Estudo}

A área de estudo compreende a bacia hidrográfica do córrego das Vacas, localizada na região oeste de Goiás, nos municípios de Diorama e Iporá, cerca de $7 \mathrm{~km}$ à oeste do centro urbano de Diorama e a $38 \mathrm{~km}$ de Iporá, e $258 \mathrm{~km}$ de Goiânia, (conforme Figura 2). A bacia localiza-se no quadrante de coordenadas $16^{\circ} 12^{\prime} 00^{\prime \prime}$ e $16^{\circ} 18^{\prime} 20^{\prime \prime}$ de latitude e $51^{\circ} 24^{\prime} 00^{\prime \prime}$ e $51^{\circ} 18^{\prime} 00^{\prime \prime}$ longitude. A figura 2 mostra o mapa de localização da bacia.

A bacia apresenta uma área de $49,8 \mathrm{~km}^{2}$ e faz parte da bacia hidrográfica do rio dos Bois ou das Almas, que por sua vez, integra a Região Hidrográfica do Rio Araguaia. O córrego das Vacas drena toda a extensão da área que delimita a bacia.

A vegetação é composta por cerrado e matas ciliares, e o uso principal da terra é por pastagem. Considerando que o relevo é ondulado, os solos predominantes são Neossolos litólicos e cambissolos em função da declividade das encostas, o cerrado por sua vez 


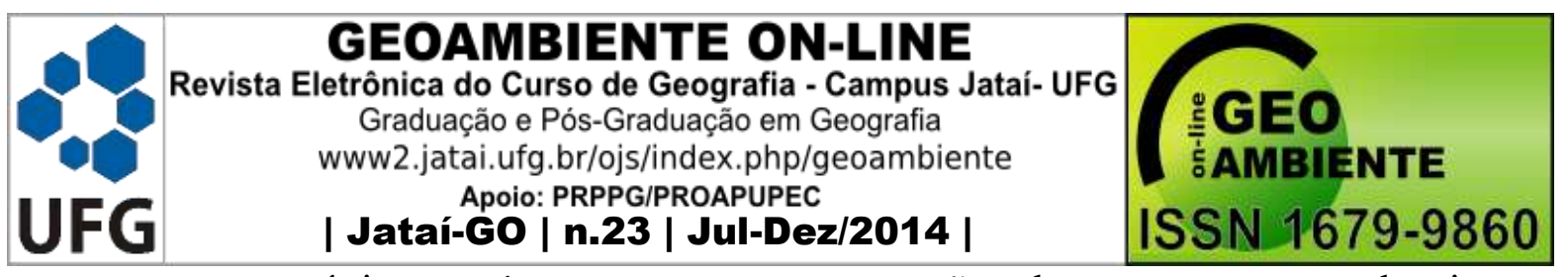

apresenta características strictu sensu, com vegetação aberta e estratos arbustivos e gramíneos, exceto nos sopés das encostas, onde predominam solos mais profundos e maior umidade, onde é possível perceber vegetação de maior porte e sem características escleromórficas.

Figura 2: Localização da bacia hidrográfica do córrego das Vacas.

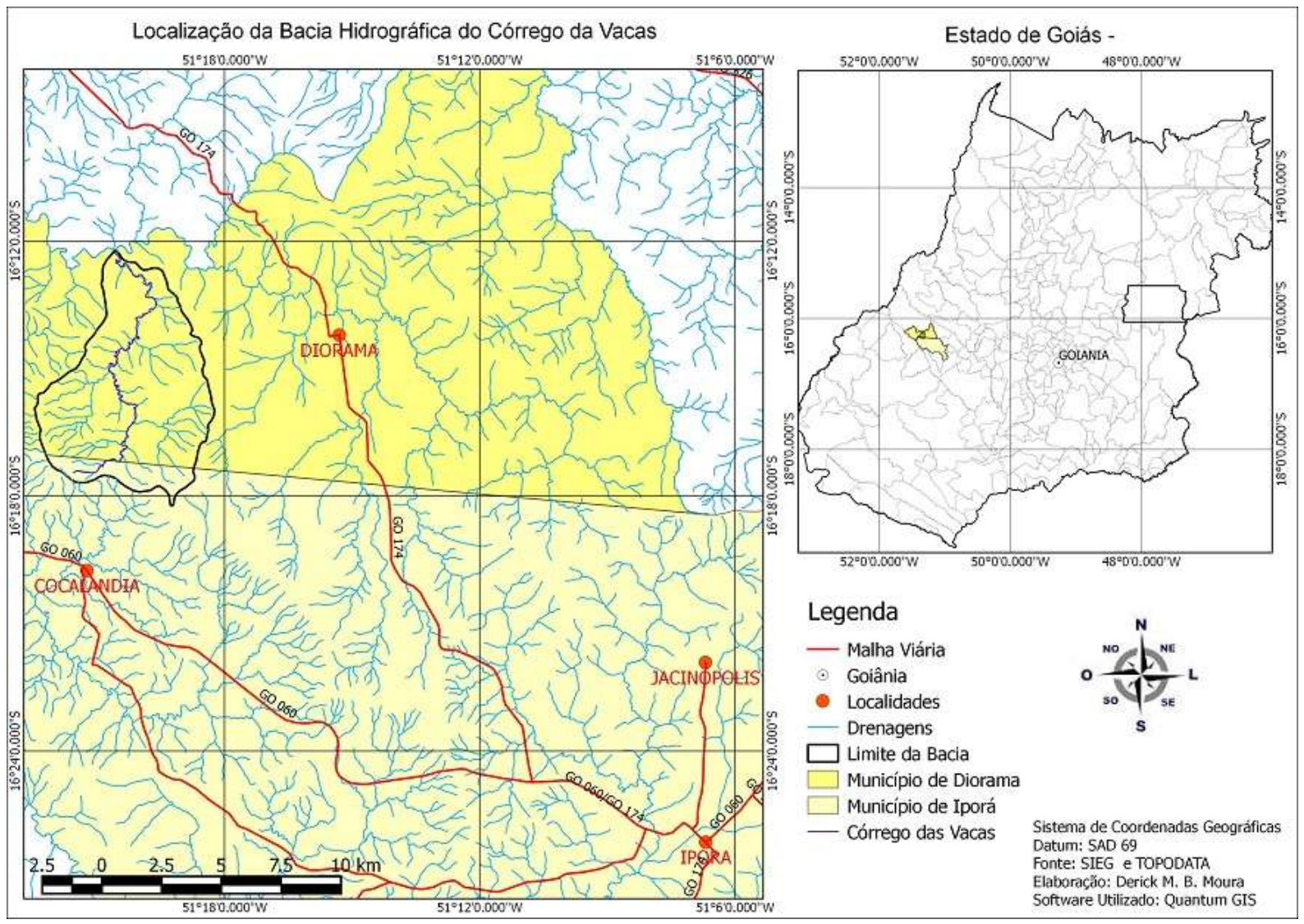

Fonte: SIEG e TOPODATA. Elaboração: Moura, 2014.

O perímetro da bacia é formado por divisores com estruturas diferentes. A leste predomina escarpas sustentadas por sedimentos da Formação Ponta Grossa, enquanto a oeste e sul, predominam divisores sustentados por estrutura Paleozóica predominantemente granítica.

\section{Procedimentos Metodológicos}

Um dos procedimentos adotados inicialmente foi o controle de campo em relação ao mapeamento geológico executado pela CPRM, com coleta de amostras de rochas in loco e conferindo se a rocha encontrada coincidia com o que foi mapeado pela CPRM. Para isso foi feito um percurso em campo abrangendo todas as ocorrências litológicas mapeadas. As rochas 


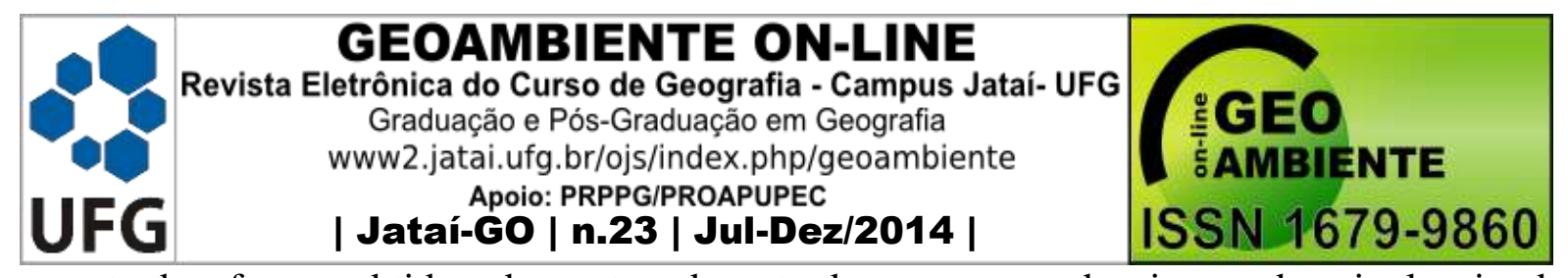

amostradas foram obtidas de cortes de estradas, margens de rios e demais locais de afloramento. Posteriormente foram identificadas conforme suas características morfológicas e mineralógicas e fotografadas. Cada ponto de coleta foi localizado com uso de GPS.

Para melhor compreensão da área de estudo, foram elaborados mapas temáticos a partir de dados disponibilizados pelos órgãos INPE, CPRM e SIEG, com o uso de softwares geotecnológicos, como o Quantum Gis e o Terra Hidro. No Quantum Gis foi gerado o MDT da área que compreende a bacia hidrográfica do córrego das Vacas, a base de dados foi a imagem SRTM disponibilizada pelo TOPODATA. No Terra Hidro foram geradas as drenagens a partir da imagem SRTM do TOPODATA. O mapa geológico foi elaborado a partir de dados disponibilizados pela CPRM e pela SIEG, e confeccionado no Quantum Gis.

Com vistas ao melhor entendimento da erosão diferencial na configuração da morfologia da bacia, foi estabelecida uma tabela com critérios numéricos para as diferentes litologias presentes na bacia. O número aumenta conforme aumenta a resistência da rocha ao intemperismo, resistência esta, estabelecida conforme a composição mineralógica das mesmas.

Através dos mapas citados foi realizada a análise da evolução do relevo que compreende a bacia hidrográfica.

\section{Resultados e discussões}

\subsection{Descrição geomorfológica}

A bacia hidrográfica do córrego das Vacas está inserida em uma superfície regional de aplainamento situada no compartimento geomorfológico regional caracterizado como Planaltos e Chapadas da Bacia Sedimentar do Paraná - Planalto Setentrional da Bacia do Paraná, descritos por Mamede et.al. (1983), apresentando cotas altimétricas entre 400m e $850 \mathrm{~m}$ e desenvolvida sobre rochas que datam da era do Pré-cambriano ao Cenozóico.

A dissecação varia de fraca a muito forte com declividade entre $3 \%$ e $12 \%$, num sistema denudacional que gerou relevo entre suave ondulado a escarpado.

O desnível do Córrego das Vacas desde sua nascente até sua foz é de $240 \mathrm{~m}$, resultando num gradiente de $12,12 \mathrm{~m} / \mathrm{km}$, que caracteriza uma dissecação mediana da sua área de drenagem. O padrão de drenagem é dendrítica e apresenta um canal de drenagem principal de $3^{\text {a }}$ ordem conforme classificação de Horton (1956) apud Christofoletti (1980). 


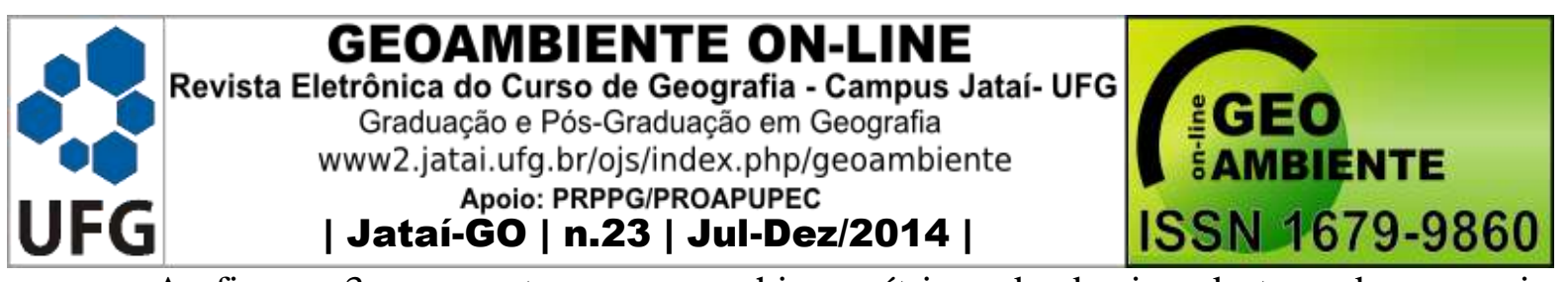

A figura 3 apresenta o mapa hipsométrico da bacia, destacando o maior aprofundamento da drenagem próximo ao divisor de margem oeste, onde há menor resistência litológica.

Figura 3: Altimetria da bacia hidrográfica do córrego das Vacas.

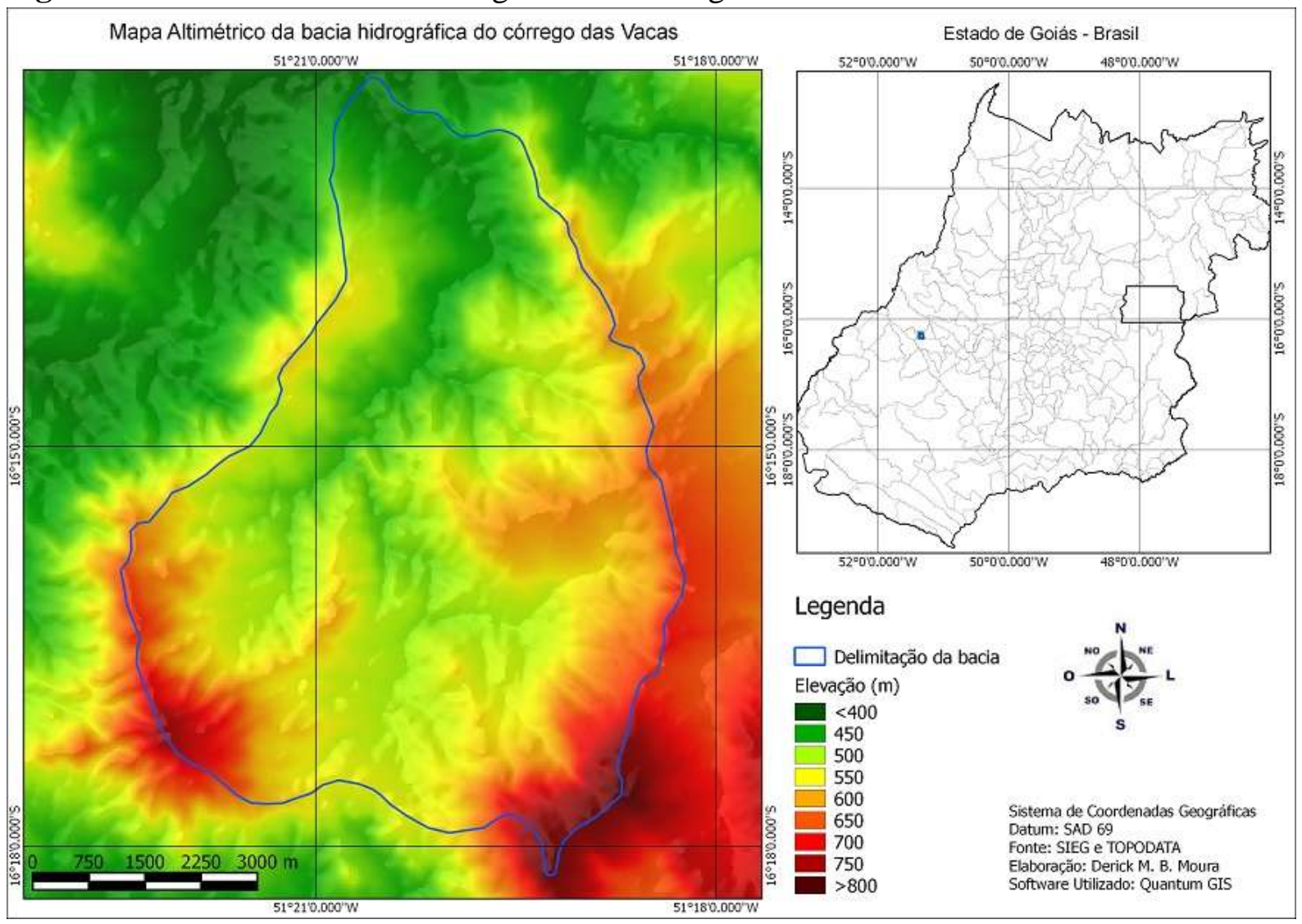

Fonte: SIEG e TOPODATA. Elaboração: Moura, 2014.

\subsection{Descrição geológica}

A geologia da bacia está apresentada de maneira mais detalhada, pois representa o principal fator no processo degradacional, que nesse estudo está embasado no grau de resistência das rochas aos processos de meteorização.

\subsubsection{Grupo Paraná - Formação Furnas}

De acordo com Alvarenga e Guimarães (1994), são rochas de Arenitos esbranquiçados a róseos, sedimentos arenosos mal selecionados, sequências sedimentares consolidadas, areno, síltico, argilo, conglomerática. A Formação Furnas ocorre em áreas isoladas, como os morros-testemunhos próximos de Arenópolis, Diorama e Iporá. 


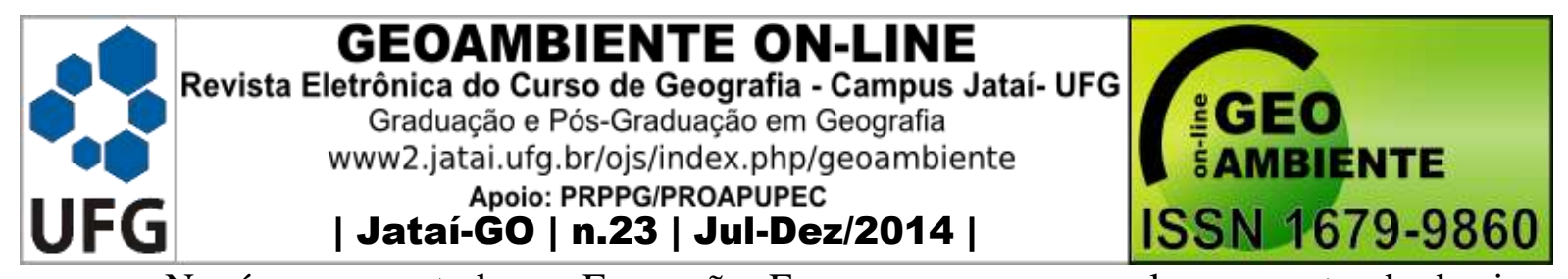

$\mathrm{Na}$ área em estudo, a Formação Furnas aparece ao sul e a norte da bacia e principalmente a leste da bacia capeando rochas mais antigas e formando o principal divisor a leste.

\subsubsection{Grupo Paraná - Formação Ponta Grossa}

Conforme a descrição de Alvarenga e Guimarães (1994), a formação Ponta Grossa é composta de folhelhos cinza a marrom-avermelhados intercalados de arenitos brancos a marrons ou esverdeados, finos a muito finos, micáceos, feldspáticos, finamente estratificados. Entre Diorama e Amorinópolis, existe uma superfície de descontinuidade dos arenitos da Formação Furnas e os arenitos e folhelhos com fósseis marinhos da Formação Ponta Grossa.

A Formação Ponta Grossa aparece a leste da bacia capeando a Formação Furnas e formando o reverso de cuesta da margem direita da bacia.

\subsubsection{Grupo Rio Ivaí - Formação Vila Maria}

Faria, (1982) e Gray et al., (1985) descrevem a formação contendo Diamictitos vermelho-arroxeados com seixos de diversas rochas, capeados por Siltitos e Folhelhos cinzaesverdeados a marron. Para o topo ocorrem Arenitos finos róseo-avermelhados, calcíferos, laminados, micáceos, às vezes feldspáticos, com microestratificação cruzada, e intercalações de Siltito e Folhelho.

A Formação Vila Maria ocorre na bacia hidrográfica do córrego das vacas, em sua porção central, e em menores elevações, devido à menor resistência do material.

\subsubsection{Granitos da Suíte Rio Caiapó}

Pimentel e Fuck, (1987a) descrevem que a Suíte Rio Caiapó é um conjunto de batólitos que ocorrem nas proximidades de Arenópolis. São rochas intrusivas e metamórficas como os Gnaisses do Arco Magmático de Goiás. As rochas dessa Suíte compreendem Granito, Granodiorito e Monzogranito e Gnaisses.

A Suíte Rio Caiapó ocorre na bacia hidrográfica na porção sudoeste sob forma de relevo de topo convexo formando os principais divisores a oeste da bacia.

\subsubsection{Sequência Metavulcanossedimentar Iporá-Amorinópolis}

Pimentel e Fuck, (1992a) e Franco et al. (1994), descrevem a unidade sendo sequências vulcanosedimentares dobradas metamorfizadas em condições de baixo a médio 


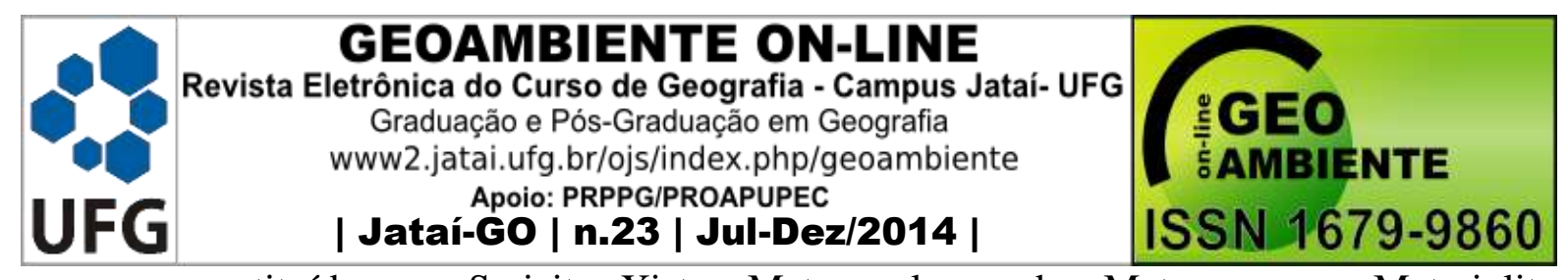

grau, e constituída por Sericita Xisto, Metaconglomerado, Metagrauvaca, Metariolito, Metatufo e Metadacito.

A Sequência Metavulcanossedimentar Iporá-Amorinópolis ocorre na bacia hidrográfica na porção central e sudoeste, representada por Sericita xisto e Metariolito, respectivamente, conforme coletado em campo.

\subsubsection{Suíte Sudoeste de Goiás}

Danni e Campos, (1994) descrevem a Suíte como sendo um conjunto de sills, diques, stocks e batólitos gabro-dioríticos que ocorrem na região sudoeste de Goiás, intrusivos em rochas das sequências Iporá-Amorinópolis. Compreendem Dioritos, Gabros Quartzodioritos, Monzodioritos, Hornblenda, Diorito pórfiro e Microdioritos.

A suíte sudoeste de Goiás ocorre na bacia hidrográfica na porção sul sob a forma de Dioritos.

\subsubsection{Complexo Alcalino Iporá}

Segundo Pena \& Figueiredo (1972), o complexo compreende pequenas intrusões na Formação Furnas e unidades mais antigas. É composto por Dunitos, Peridotitos, Piroxenitos, Serpentinitos, Gabros, Sienogabros, Nefelina sienitos, Silexitos, Carbonatitos, Kimberlitos e Lamprófiros. Os corpos localizam-se na região oeste de Goiás onde se destacam os seguintes maciços: Maciço do Rio dos Bois - núcleo de dunito, e Fazenda Buriti - situado a noroeste de Iporá e consiste de Olivina clinopiroxenito, Melanogabro, Essexito, Sienogabro e Sienito.

O complexo alcalino Iporá ocorre na bacia hidrográfica na porção nordeste sob as formas de Dunito.

\subsubsection{Ortognaisses do Oeste de Goiás}

Descritos por Pimentel e Fuck (1992b), como ortognaisses neoproterozóicos do Arco Magmático de Goiás. Compreende Ortognaisse Tonalítico, Gnaisse Ortoderivado e Complexos Granito-gnaisse-migmatitos e Granulitos.

A Unidade Ortognaisses do Oeste de Goiás ocorre na bacia hidrográfica na porção noroeste sob a forma de Gnaisse.

As diferentes litologias contidas na bacia hidrográfica do córrego das vacas foram identificadas no trabalho de campo, sendo coletadas, fotografadas e georreferenciadas, como podemos notar nas figuras 4 e 5 . 


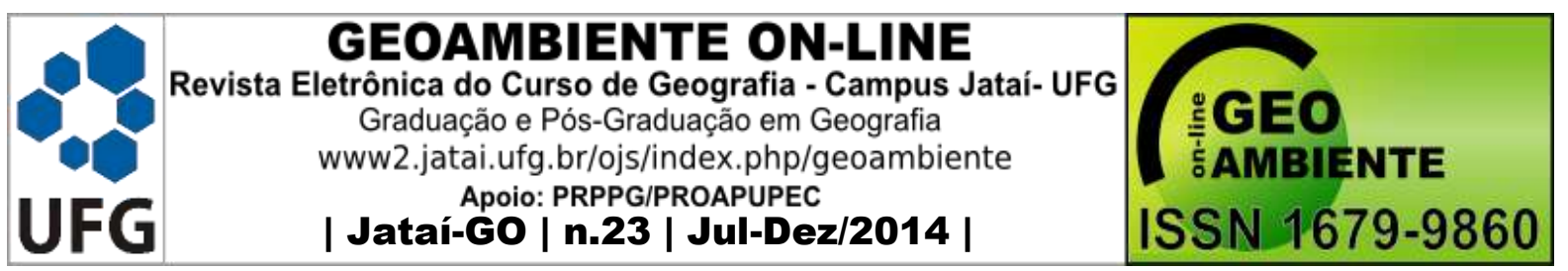

Podemos verificar com o mapeamento geológico, que a bacia hidrográfica do córrego das Vacas é bastante diversificada, contendo rochas de idades variadas desde o PréCambriano até o Cenozóico, resultando em composições diferentes e gerando resistências diferentes aos processos degradacionais do relevo. A Figura 5 mostra as unidades geológicas e suas distribuições geográficas na bacia.

Figura 4: Fotografias do trabalho de campo. A: Granito. B: Dunito. C: Diorito. D: Gabro. E: Arenito. F: Gnaisse. G: Folhelho. H: Sericita Xisto aflorando no córrego das Vacas. I: Caos de blocos de Diorito.
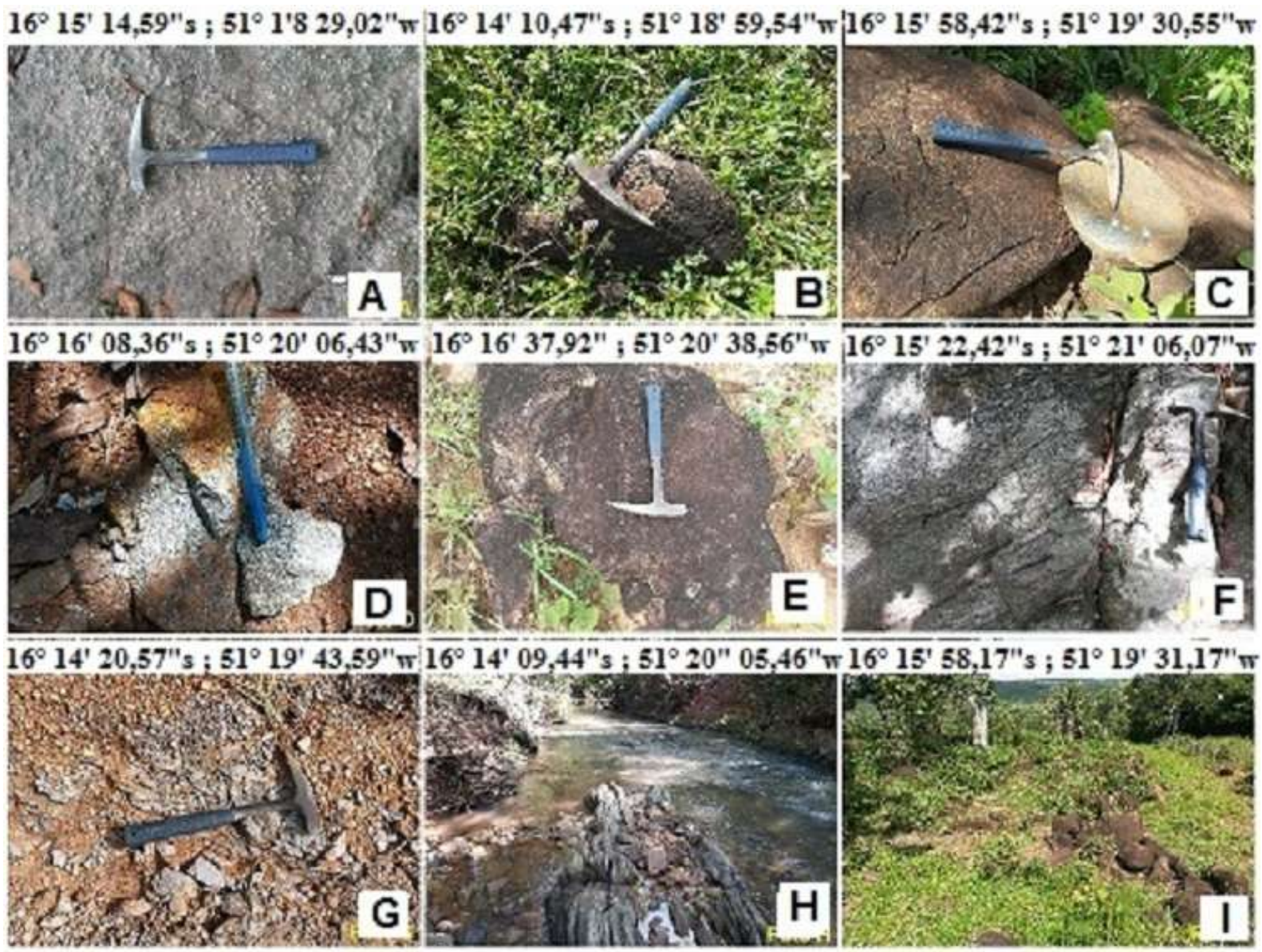

Fonte: Moura, 2014. 


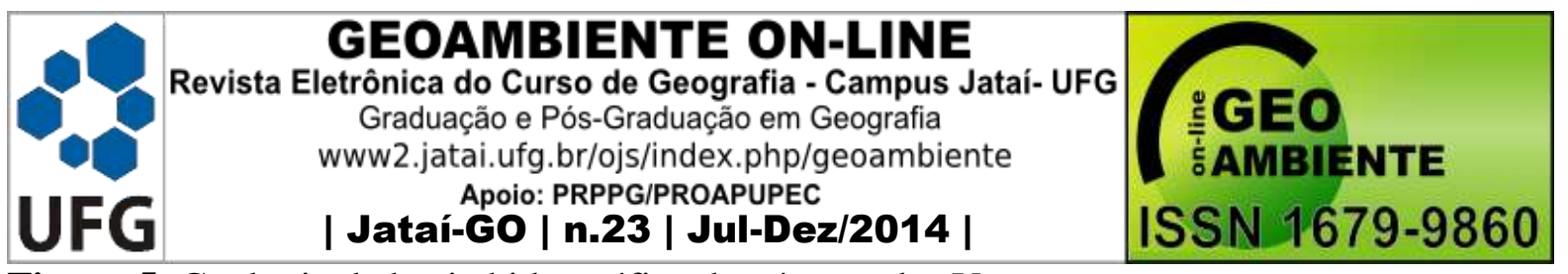

Figura 5: Geologia da bacia hidrográfica do córrego das Vacas.

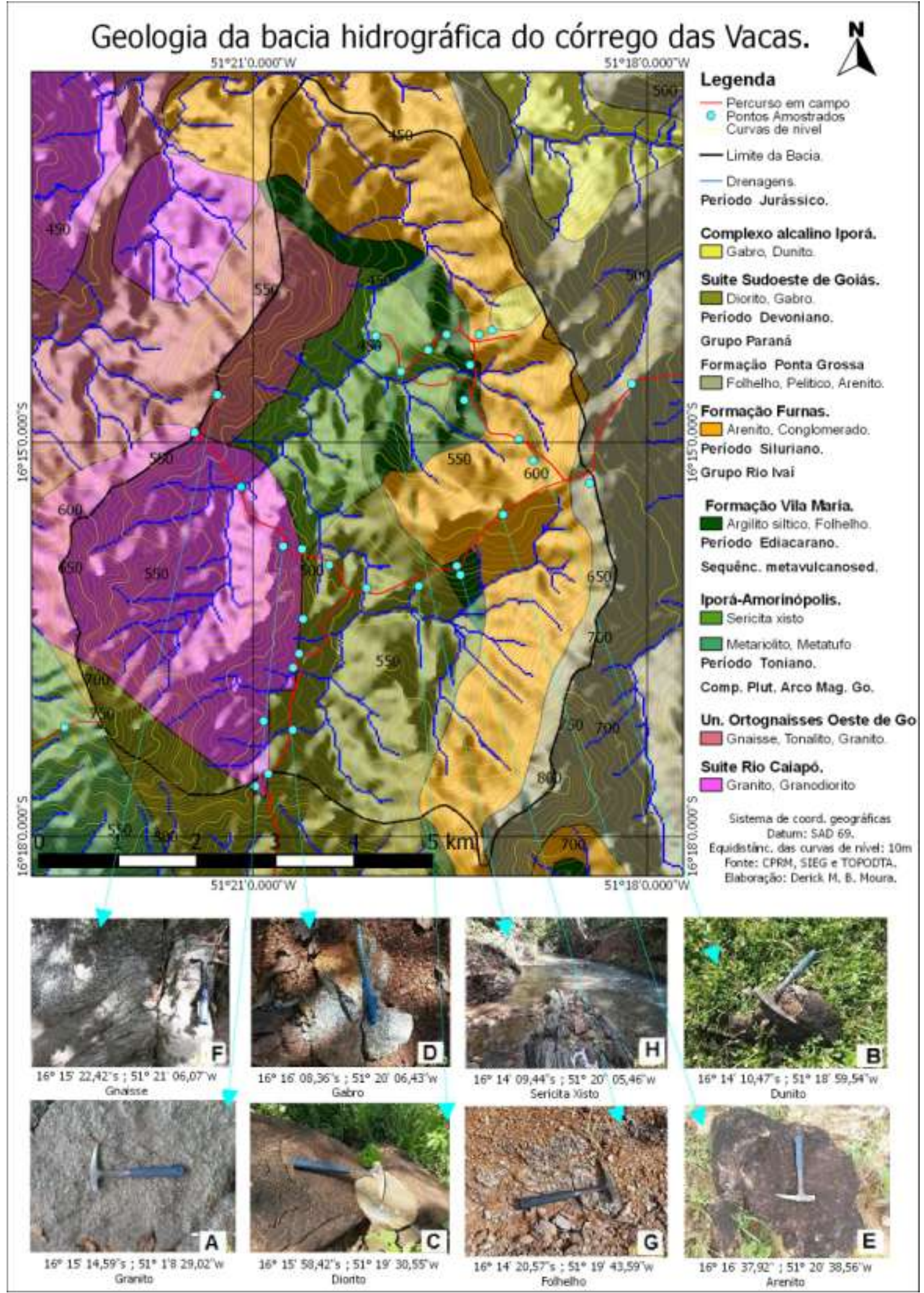

Fonte: SIEG, CPRM e TOPODATA. Elaboração: Moura, 2014. 


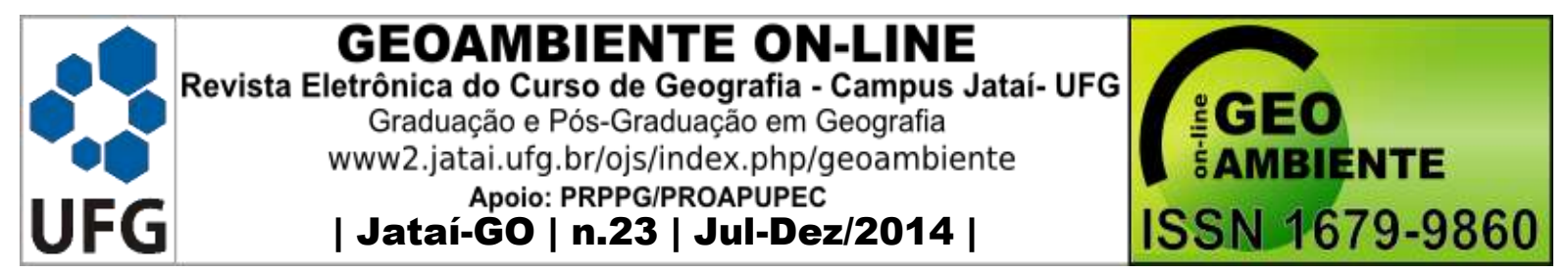

Como visualizado através da figura 5, existem nove diferentes grupos de rochas na bacia hidrográfica. A litologia foi dividida conforme as unidades geológicas, a idade das rochas através dos diferentes períodos e os grupos de rochas foram classificados por ordem numérica de resistência ao intemperismo conforme composição mineralógica.

O quadro 1 ilustrado a seguir, classifica a litologia contida na bacia hidrográfica do córrego das Vacas conforme os graus de resistência ao intemperismo, idade, período e unidade geológica.

Quadro 1: classificação litológica da bacia hidrográfica do córrego das Vacas.

\begin{tabular}{|c|c|c|c|c|}
\hline Litologia & $\begin{array}{l}\text { Unidade } \\
\text { geológica }\end{array}$ & Período & $\begin{array}{c}\text { Idade (milhões } \\
\text { de anos) }\end{array}$ & $\begin{array}{c}\text { Grau de resistência ao } \\
\text { intemperismo }\end{array}$ \\
\hline Dunito, Gabro & $\begin{array}{c}\text { Complexo } \\
\text { alcalino Iporá }\end{array}$ & Jurássico & 66 & 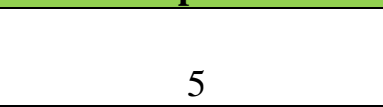 \\
\hline Diorito, Gabro & $\begin{array}{c}\text { Suíte Sudoeste } \\
\text { de Goiás }\end{array}$ & Jurássico & 123 & 6 \\
\hline Folhelho, Pelítico & $\begin{array}{c}\text { Grupo Paraná - } \\
\text { Formação Ponta } \\
\text { Grossa }\end{array}$ & & 356 & 3 \\
\hline $\begin{array}{c}\text { Arenito, } \\
\text { Conglomerado } \\
\end{array}$ & $\begin{array}{c}\text { Grupo Paraná - } \\
\text { Formação Furnas }\end{array}$ & Devoniano & 390 & 1 \\
\hline $\begin{array}{l}\text { Argilito síltico, } \\
\text { Folhelho }\end{array}$ & $\begin{array}{c}\text { Grupo Rio Ivaí - } \\
\text { Formação Vila } \\
\text { Maria } \\
\end{array}$ & Siluriano & 426 & 2 \\
\hline $\begin{array}{l}\text { Metariolito, } \\
\text { Metatufo, } \\
\text { Metadacito }\end{array}$ & $\begin{array}{c}\text { Sequência } \\
\text { metavulcanos- } \\
\text { sedimentar } \\
\text { Iporá- } \\
\text { Amorinópolis - } \\
\text { Unidade 2 }\end{array}$ & & 597 & 7 \\
\hline $\begin{array}{c}\text { Sericita xisto, } \\
\text { Metaconglomerad } \\
\text { o, Metagrauvaca }\end{array}$ & $\begin{array}{l}\text { Sequência } \\
\text { metavulcanos- } \\
\text { sedimentar } \\
\text { Iporá- } \\
\text { Amorinópolis - } \\
\text { Unidade } 3\end{array}$ & Ediacarano & 597 & 4 \\
\hline $\begin{array}{c}\text { Gnaisse, Tonalito, } \\
\text { Granito }\end{array}$ & $\begin{array}{l}\text { Complexo } \\
\text { Plutônico do } \\
\text { Arco Magmático } \\
\text { de Goiás - } \\
\text { Unidade } \\
\text { Ortognaisses do } \\
\text { Oeste de Goiás }\end{array}$ & & 856 & 8 \\
\hline $\begin{array}{c}\text { Granito, } \\
\text { Granodiorito }\end{array}$ & Suíte Rio Caiapó & Toniano & 1000 & 9 \\
\hline
\end{tabular}

Fonte: Moura, 2014. 


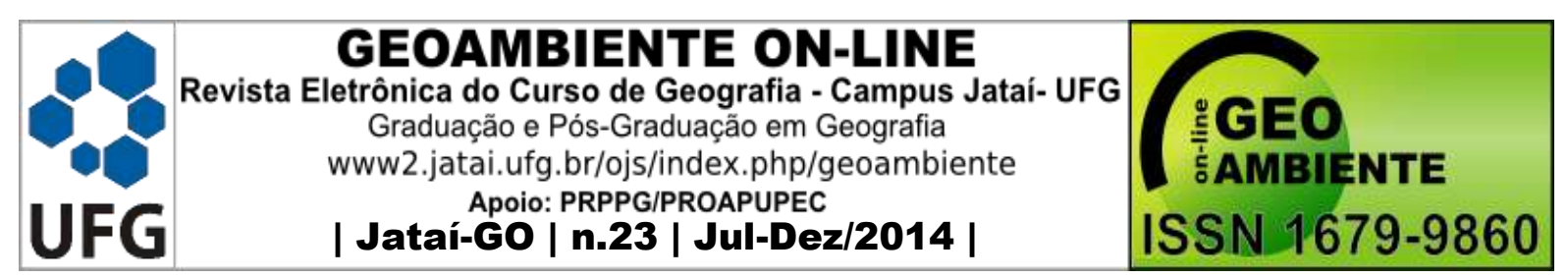

Observando a dissecação da bacia e correlacionando isso ao grau de resistência das rochas é possível perceber que dois fatores influenciaram na modelagem da bacia, quais sejam, o fator altitude e o fator resistência das rochas.

O fator altitude predomina no lado leste da bacia onde se encontram coberturas sedimentares compostas pelas formações Furnas e Ponta Grosa. Embora o grau de fragilidade das rochas seja 1, a ruptura de declive naquela posição assinala com declividades mais acentuadas fazendo prevalecer a morfogênese, em relação à pedogênese.

O fator resistência prevalece no sentido oeste/centro da bacia, onde é possível notar que os divisores a oeste são formados por rochas graníticas/gnáissicas que possuem grau de resistência ao intemperismo entre 8 e 9, havendo um decréscimo de altitude e aumento do entalhamento do talvegue em direção ao centro da bacia, formando uma sequência de diminuição da resistência litológica conforme a direção do fluxo, ou seja, o fluxo do rio principal segue a sequência de resistências de maior para menor $6,4,1$, como é possível perceber na figura 6 .

Figura 6. Esquema do entalhamento da drenagem em função da resistência da rocha e da altitude.

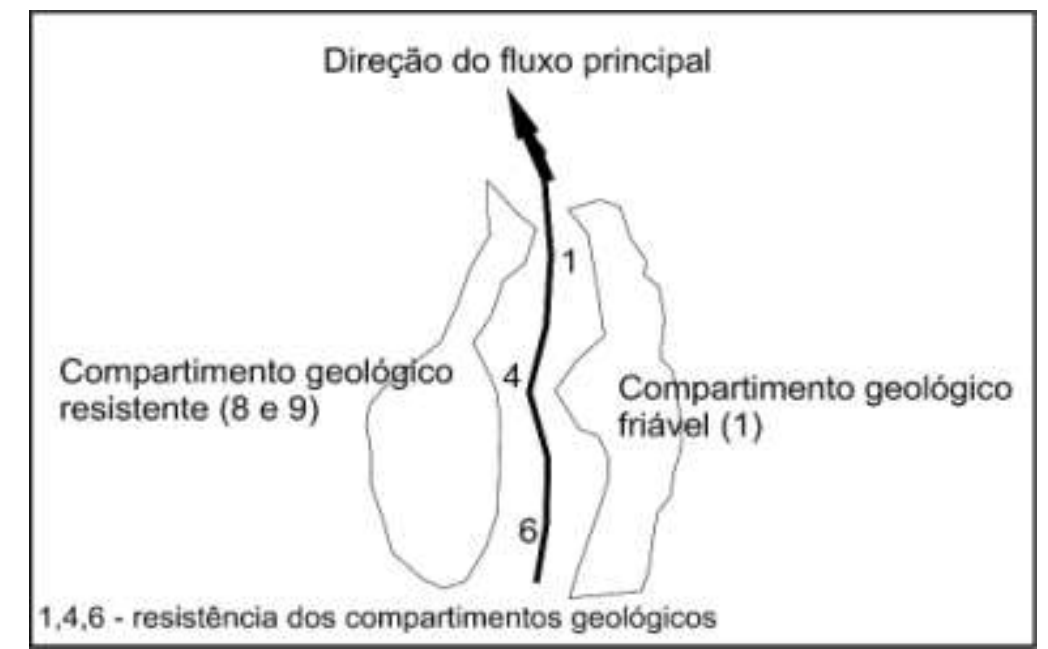

Fonte: Moura, 2014.

\section{Considerações Finais}

A bacia resulta de um entalhamento da drenagem que segue duas leis da geomorfologia, quais sejam, a lei da declividade e a lei da estrutura, ambas propostas por Gilbert (1877) descritas por Ross (1990), porém, antes de destacar suas ações, é necessário destacar a origem estrutural da região. 


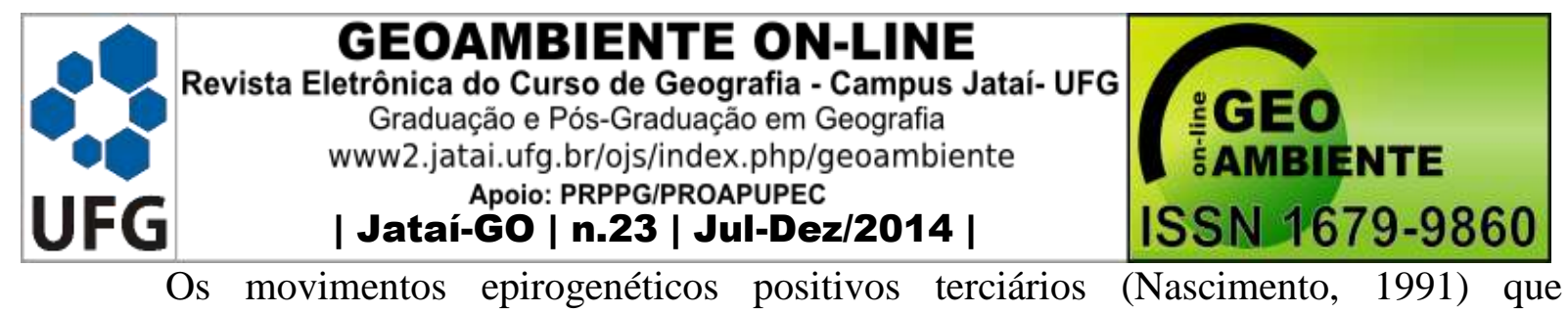

suspenderam a região do Planalto Setentrional da Bacia do Paraná, alteraram todo o sistema de dissecação do relevo, reativando os processos de drenagem e favorecendo os processos degradacionais. A borda noroeste da bacia sedimentar do Paraná onde estão os municípios de Iporá e Diorama foi afetada por processos intrusivos de sin-epirogênese e idades cenozóicas, que levantaram áreas de cobertura sedimentar, principalmente formadas pelas formações Furnas e Ponta Grossa e provocaram metamorfização.

As áreas de maior influência da declividade (Lei da declividade) foram entalhadas primeiramente por influência da superimposição da drenagem, removendo materiais de menor resistência e exumando rochas intrusivas mais antigas como os granitos.

A bacia do córrego das vacas tem uma configuração diferenciada das demais em função de um conjunto de eventos ligados à erosão diferencial, que lhe proporcionaram uma forma mais exótica.

As coberturas sedimentares ao centro da bacia foram exumadas e removidas com maior facilidade, enquanto as bordas da margem direita apresentam predominância de maiores declividades, ficando preservadas como divisores de água e em forma de escarpa erosiva em direção ao centro da bacia, formando um reverso de cuesta no sentido leste do divisor.

\section{Referências}

ALVARENGA, C.J.S. de; GUIMARÃES, E.M. Siluro-Devoniano na Margem Noroeste da Bacia do Paraná, Região entre Diorama e Amorinópolis, GO. In: Simpósio de Geologia do Centro-Oeste, 4, 1994, Brasília, Anais ... Brasília: SBG, 1994. p. 53-54.

CARVALHO, T.M.; LATRUBESSE, E.M. (2004) $O$ uso de modelos digitais do terreno (MDT) em análises macrogeomorfológicas: o caso da bacia hidrográfica do Araguaia. Revista Brasileira de Geomorfologia, 5(1):85-93p.

CASSETI, Valter. Geomorfologia. [S.1.]: [2005]. Disponível em: <http://www.funape.org.br/geomorfologia/>. Acesso em: 15 de maio de 2014.

CHRISTOFOLETTI, A. Geomorfologia. Editora: Edgard Blücher, São Paulo, $2^{\circ}$ edição, 1980.

DANNI, J.C.M.; CAMPOS, J.E.G. Geologia e Petrologia do Complexo Cachoeira do Lajeado, Iporá, Goiás. In: Simpósio de Geologia do Centro-Oeste, 4, 1994, Brasília, Anais ... Brasília: SBG, 1994. 


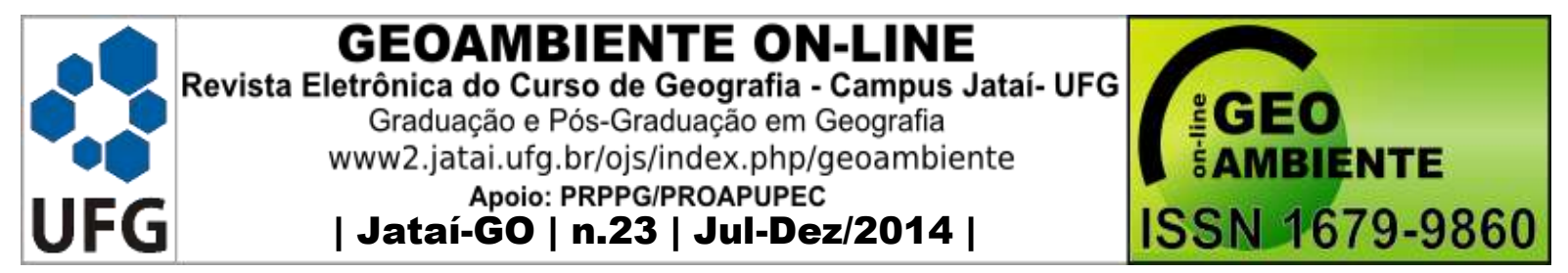

FARIA, A. de Formação Vila Maria Nova Unidade Litoestratigráfica Siluriana da Bacia do

Paraná. Ciências da Terra, n.3, p.12-15, 1982.

FELGUEIRAS, C.A. (1997) Análises sobre modelos digitais de terreno em ambientes de sistemas de informação geográfica. In: VIII Simpósio Latino Americano de Percepcíon Remota y Sistemas de Información Espacial. Mérida, Venezuela.

FRANCO, H.A.; CAMPOS, J.E. G.; DANNI, J.C.M. A Sequência Vulcano-sedimentar Iporá/Amorinópolis: Uma Contribuição. In: Congresso Brasileiro de Geologia, 38, 1994, Camboriú. Res. Expandidos... Camboriú: SBG, 1994. v.3, p.108-110.

JATOBÁ, L.; LINS, R. C. Introdução à Geomorfologia. $2^{\circ}$ Edição. Recife. Editora Bagaço, 1998.

MACHADO, L.E.G.; LIMA, V.C de. Mapeamento geomorfológico da bacia do rio Água Limpa $(G O)$ com base em parâmetros morfométricos e morfográficos. Ateliê Geográfico v. 7, n. 3, p.79-109, 2013.

MAMEDE L. et al. Levantamento Geomorfológico. Projeto Radambrasil (Folha SE.22 Goiânia). Rio de Janeiro: MME,1983. (Levantamento de Recursos Naturais 31).

NASCIMENTO, M. A. L.S. Geomorfologia do Estado de Goiás. Boletim Goiano de Geografia, v.12 n.1 (jan/dez). UFG, 1991.

NETTO, A. L. C; Hidrologia de Encosta na Interface com a Geomorfologia. In Geomorfologia uma atualização de bases e conceitos, Rio de Janeiro, 2003, p 93-148.

PENA, G.S.; FIGUEIREDO, A.J. Projeto Alcalinas - Relatório Final. Goiânia: DNPM/CPRM, 1972. 143 p. (Conv. DNPM/CPRM).

PIMENTEL, M.M.; FUCK, R.A. Características geoquímicas e isotópicas de unidades metavulcânicas e ortognáissicas neoproterozóicas do oeste de Goiás. Boletim da Sociedade. Brasileira de Geologia - Núcleo Centro-Oeste, n.15, p.1-22, 1992b.

PIMENTEL, M.M.; FUCK, R.A. Origem e evolução das Rochas Metavulcânicas e Metaplutônicas da Região de Arenópolis-GO. Revista Brasileira de Geociências, São Paulo, v.17, n.1, p.2-14, 1987a.

ROSS, J. L. S. Geomorfologia: Ambiente e Planejamento. São Paulo: Contexto, 1990.

ROSS, J. L. S. O Registro Cartográfico dos Fatos Geomorfológicos e a Questão Taxonômica do Relevo. Revista do Departamento de Geografia - USP. EDUSP Editora. N 6, Pg: 17 - 30. 1992.

SIEG. Sistema Estadual de Geoinformação de Goiás. Mapas em formato shapefile. Disponível em: <www.sieg.go.gov.br>. Acesso em: 15 mai. 2014. 


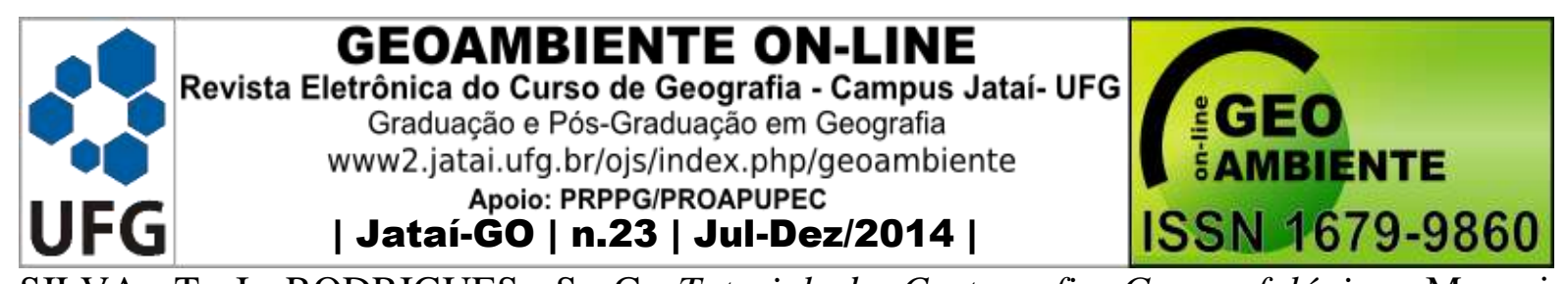

SILVA, T. I; RODRIGUES, S. C; Tutorial de Cartografia Geomorfológica. Manuais Técnicos - Revista Geográfica Acadêmica, v.3, n.2. 2009.

SILVA, T. M. Superficies geomorfológicas no Planalto Sudeste brasileiro: revisão teóricoconceitual. Geo UERJ, v. 3, n. 20, p. 1-22, 2009.

SOUSA, F. A de. A contribuição dos solos originados sobre granitos e rochas alcalinas na condutividade hidráulica, na recarga do lençol freático e na suscetibilidade erosiva - um estudo de caso na alta bacia hidrográfica do rio dos bois em iporá-GO. (Tese de doutorado). Uberlândia. UFU, Programa de Pesquisa e Pós-Graduação em geografia. 2013. 207p. 